\title{
The Kinesin Motor KIF3A Is a Component of the Presynaptic Ribbon in Vertebrate Photoreceptors
}

\author{
Virgil Muresan, Asya Lyass, and Bruce J. Schnapp \\ Department of Cell Biology, Harvard Medical School, Boston, Massachusetts 02115
}

Kinesin motors are presumed to transport various membrane compartments within neurons, but their specific in vivo functions, cargoes, and expression patterns in the brain are unclear. We have investigated the distribution of KIF3A, a member of the heteromeric family of kinesins, in the vertebrate retina. We find KIF3A at two distinct sites within photoreceptors: at the basal body of the connecting cilium axoneme and at the synaptic ribbon. Immunoelectron microscopy of the photoreceptor ribbon synapse shows KIF3A to be concentrated both at the ribbon matrix and on vesicles docked at the ribbon, a result that is consistent with the presence of both detergent-extractable and resistant KIF3A fractions at these synapses. KIF3A is also present in the inner plexiform layer, again at presynaptic ribbons. These findings suggest that within a single cell, the photoreceptor, one kinesin polypeptide, KIF3A, can serve two distinct functions, one specific for ribbon synapses.

Key words: retina; photoreceptor cell; bipolar cell; ribbon synapse; connecting cilium axoneme; intracellular traffic; kinesin-related motor KIF3A
Kinesins constitute a large family of microtubule motor proteins that convert the energy of ATP hydrolysis into directed movement along microtubules, presumably for the purpose of carrying intracellular cargoes to various destinations (Vale et al., 1985; Coy and Howard, 1994; Hirokawa, 1998). Although at least 30 different kinesin motors are expressed in brain (Nakagawa et al., 1997), their in vivo functions and cargoes are still unclear, as is the question of whether specific types of neurons express particular kinesins and not others. In fact, most neuronal kinesins have not been definitively localized at the cellular or subcellular level.

The vertebrate retina, with its accessibility and simple laminar organization, is suitable for investigating the in vivo functions of neuronal kinesins. It contains six major classes of neurons distributed within three cellular and two synaptic (plexiform) layers that accommodate two types of synapses. The outer plexiform layer (OPL) is dominated by ribbon synapses between presynaptic photoreceptors and postsynaptic horizontal and bipolar cells. The inner plexiform layer (IPL) contains synapses involving the processes of ganglion, amacrine, bipolar, and interplexiform cells. A few of these are ribbon synapses, but most are conventional (Dowling and Boycott, 1966).

Like conventional presynaptic terminals, the photoreceptor terminal relies on endocytosis and local recycling to replenish synaptic vesicles that have released their contents by exocytosis

\footnotetext{
Received Aug. 6, 1998; revised Nov. 13, 1998; accepted Nov. 20, 1998.

This work was supported by a grant to B.J.S. from National Institutes of Health (NS-26846). V.M. was supported by a Neuromuscular Disease Research Fellowship from the Muscular Dystrophy Association during the initial part of this study. We thank Drs. Joseph Besharse, Richard Masland, Elio Raviola, Tom Reese, Nancy Chamberlin, Jim Deshler, Martin Highett, and Zoia Muresan for helpf ul discussions and comments on this manuscript. We also thank Dr. Connie Cepko for the P0 and P7 retinal samples, Ms. Maria Ericsson for help with the electron microscopy, and Dr. Zoia Muresan for providing chicken retina cryosections. Taxol was a gift from the National Cancer Institute. We are grateful to Drs. George S. Bloom, Robert Burgoyne, Pietro De Camilli, and Vladimir I. Gelfand for their generous gifts of antibodies. We are especially grateful to Dr. Jonathan M. Scholey for the gift of the K2.4 (anti-KIF3A) antibody, which made this study possible.

Correspondence should be addressed to Dr. Bruce J. Schnapp, Department of Cell Biology, Harvard Medical School, 240 Longwood Avenue, Boston, MA 02115. Copyright (C) 1999 Society for Neuroscience $\quad 0270-6474 / 99 / 191027-11 \$ 05.00 / 0$
}

(Schaeffer and Raviola, 1978; Matthews, 1996). Ultimately, however, presynaptic terminal components must be transported along cytoplasmic microtubules from the site of protein synthesis in the cell body. Microtubule-based transport also supplies components of the phototransduction machinery along the connecting cilium axoneme to the outer segment at the opposite end of the cell [for review, see Besharse and Horst (1990); see also Fig. 1]. A key question is how microtubule motor proteins organize these two plus-end-directed transport pathways, which differ not only in their transported cargoes but also in their light-dependent regulation (Besharse, 1982).

Previous studies have shown that the kinesin polypeptide KIF3A, a component of the microtubule motor kinesin II (Scholey, 1996), is concentrated at the basal bodies of conventional cilia and flagella (Vashishtha et al., 1996; Henson et al., 1997), and its inhibition by genetic disruption (Perkins et al., 1986; Cole et al., 1998) or antibody injection (Morris and Scholey, 1997) blocks ciliogenesis. Although its exact cargo and function are not known, kinesin II could be involved in the transport of ciliary and flagellar components toward the plus-ends of axonemal microtubules (Kozminski et al., 1995; Cole et al., 1998).

In the present report we show that KIF3A, together with the other kinesin II components, KIF3B and KAP3, is present at the basal bodies of the connecting cilium axonemes in mammalian photoreceptor cells, where it could provide a function that is analogous to the one it provides in conventional cilia. In addition, KIF3A is concentrated at the opposite end of the photoreceptor cells in the presynaptic terminal, where it is found at the presynaptic ribbon and on its associated vesicles. These findings suggest that KIF3A is involved in both photoreceptor transport pathways.

\section{MATERIALS AND METHODS}

\section{Preparation of tissue extracts and subcellular fractionation}

Buffers used in these studies were supplemented with $1 \mathrm{~mm}$ DTT and a mixture of protease inhibitors (Muresan et al., 1996). Eyes were collected from 5-week-old male Sprague Dawley rats (killed by asphyxiation with $\mathrm{CO}_{2}$ ) and placed in ice-cold PBS, $\mathrm{pH}$ 7.3. Freshly dissected retinas were 


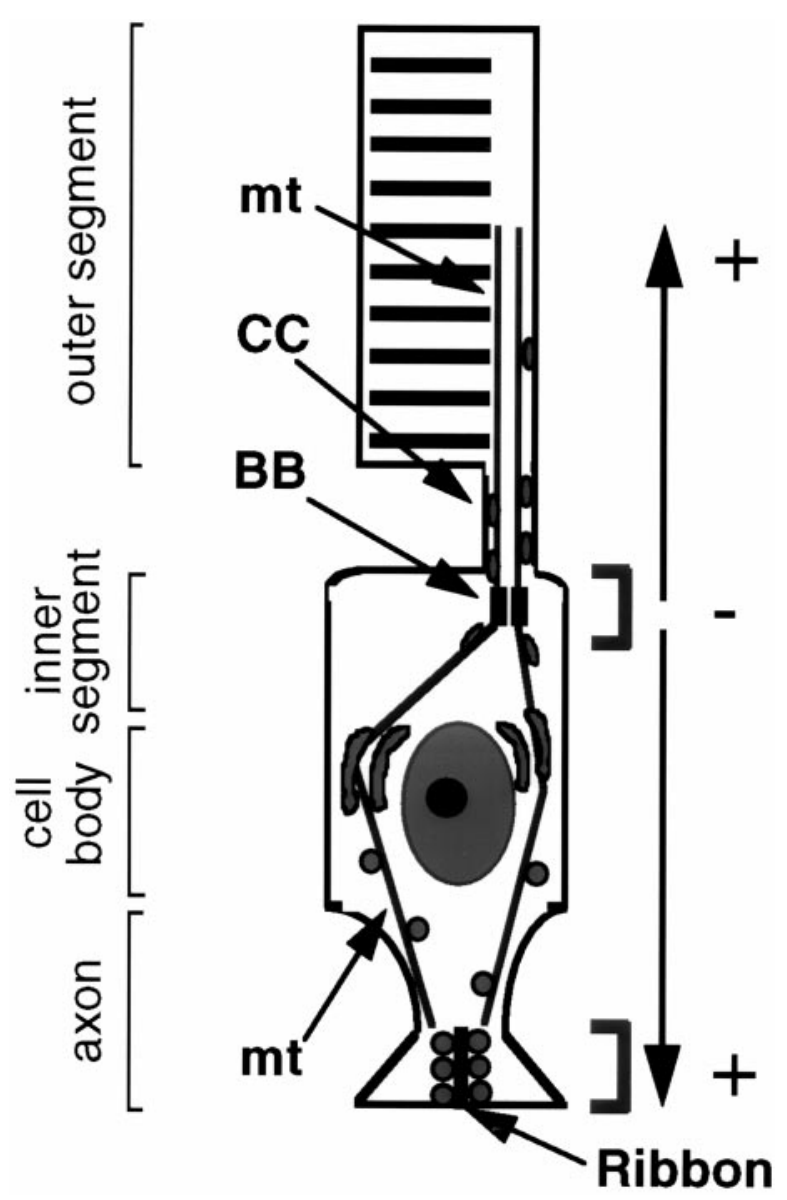

Figure 1. Microtubule network in a rod photoreceptor. One pathway delivers material toward the outer segment along the connecting cilium $(C C)$ axoneme, the other carries Golgi-derived vesicles to the synaptic terminal along cytoplasmic microtubules. Arrows indicate microtubule $(m t)$ polarity. Brackets show the two sites of KIF3A localization: the basal body $(B B)$ of the connecting cilium axoneme, and the synaptic ribbon.

cut into small pieces, homogenized in a minimal amount of buffer in an Eppendorf tube with a small Teflon pestle, supplemented with an equal volume of $2 \times$ sample buffer, and boiled. For preparation of crude synaptic membranes, one rat retina was homogenized with a Teflon homogenizer in $100 \mu \mathrm{l}$ of $15 \mathrm{mM} \mathrm{Na}_{2} \mathrm{HPO}_{4}, \mathrm{pH}$ 7.4, supplemented with $1 \mathrm{~mm}$ EGTA, $1 \mathrm{~mm} \mathrm{MgCl}$, $1 \mathrm{~mm}$ phenylmethyl sulfonyl fluoride, and protease inhibitors (Schmitz et al., 1996). All further steps were conducted at $4^{\circ} \mathrm{C}$. The crude homogenate was overlaid over half volume of a $50 \%$ sucrose cushion and centrifuged for $1 \mathrm{hr}$ at 27,000 $\times \mathrm{g}$. Membranes were collected from the sucrose-buffer interface, diluted with 2 vol of homogenization buffer, and centrif uged for $15 \mathrm{~min}$ at $48,000 \times g$. The pellet, containing crude synaptic membranes, was resuspended in homogenization buffer and extracted for $1 \mathrm{hr}$ on ice with $1 \%$ Triton $\mathrm{X}-100$. The extract was separated into a supernatant and a detergentinsoluble pellet by centrifugation for $10 \mathrm{~min}$ at $15,000 \times g$. Samples from each fraction were processed for SDS-PAGE.

To prepare photoreceptor inner and outer segments, rat retinas were suspended in $10 \mathrm{~mm}$ PIPES buffer, pH 7.0, containing $5 \mathrm{~mm} \mathrm{MgCl}_{2}$ and $50 \%$ sucrose, and sheared by several passages through an 18 gauge needle and by shaking. Photoreceptor inner and outer segments were separated from the rest of the retina by flotation $(1 \mathrm{hr}, 13,000 \times \mathrm{g})$.

A cytoskeletal fraction enriched in photoreceptor axonemes was prepared from dark-adapted, frozen bovine retinas (Excel Corporation, Rockville, MO), as described previously (Muresan and Besharse, 1994). Briefly, rod inner and outer segments, purified by sucrose density centrifugation from 50 retinas, were extracted with Triton X-100 and fractionated on a second sucrose step gradient. The axoneme fraction was obtained as a detergent-insoluble residue at the interface of the 50 and
$60 \%$ sucrose layers. Axonemal samples were then supplemented with $2 \times$ sample buffer and incubated for $4 \mathrm{~min}$ at $95^{\circ} \mathrm{C}$.

\section{Microtubule binding assay}

A rat retina homogenate, prepared in BRB80 (80 mM PIPES, pH 6.8, 1 $\mathrm{mM} \mathrm{MgCl}_{2}, 1 \mathrm{~mm}$ EGTA) supplemented with $2 \%$ Triton X-100, was diluted 1:1 with BRB80 and cleared by a 45 min centrifugation at $120,000 \times g$. Taxol-stabilized microtubules (assembled from phosphocellulose-purified bovine brain tubulin) were added to the supernatant at final concentration of $0.5 \mathrm{mg} / \mathrm{ml}$, and the mixture was supplemented with $20 \mu \mathrm{M}$ taxol, $5 \mathrm{~mm} 5^{\prime}$-adenylyl imidodiphosphate (AMP-PNP), and $5 \mathrm{mM} \mathrm{MgCl}_{2}$. After a $1 \mathrm{hr}$ incubation at $23^{\circ} \mathrm{C}$, microtubules were sedimented through a $30 \%$ sucrose cushion by centrifugation $\left(1 \mathrm{hr}, 120,000 \times g\right.$, at $\left.18^{\circ} \mathrm{C}\right)$. Pellets were resuspended and incubated in BRB80 containing $100 \mathrm{~mm} \mathrm{NaCl}$ plus $7.5 \mathrm{~mm} \mathrm{ATP}$ and $\mathrm{MgCl}_{2}$, and then subjected to centrifugation to separate released proteins from the microtubule pellet. Supernatants and microtubule pellets were analyzed by Western blotting.

\section{Immunoblotting}

SDS-PAGE in $7.5 \%$ gels, semi-dry protein transfer onto $0.2 \mu \mathrm{m}$ polyvinylidene difluoride membrane, and antibody overlay were performed as described previously (Muresan et al., 1996). Antibody binding was visualized with 4-nitroblue tetrazolium chloride and 5-bromo-4-chloro-3indolyl-phosphate. Protein concentrations in electrophoretic samples were determined with the dotMETRIC protein assay (Geno Technology, St. Louis, MO).

\section{Immunocytochemistry of frozen tissue sections}

Rat, mouse, bovine, and Xenopus laevis eyes were collected from adult animals during daytime in ice-cold PBS, enucleated, and placed in PBS containing $4 \%$ formaldehyde for $90 \mathrm{~min}$ at $23^{\circ} \mathrm{C}$. Occasionally, rat eyes were collected, enucleated, and fixed at night, under dim red light illumination. Chicken eyes were collected from 18-d-old embryos. Eyecups or segments of eyecups were washed in PBS, transferred successively to buffers containing increasing sucrose concentrations, and finally embedded by freezing in a 2:1 mixture (v/v) of 20\% sucrose-PBS and Tissue-Tek O.C.T. compound (Miles, Elkhart, IN) (Barthel and Raymond, 1990). Sections 7- to 10- $\mu \mathrm{m}$-thick were collected on Superfrost/ Plus microscope slides (Fischer Scientific, Pittsburgh, PA), air-dried, and kept at $-20^{\circ} \mathrm{C}$ until use. Fresh-frozen sections were prepared similarly, but the fixation step was omitted. These sections were then extracted with $1 \%$ Triton X-100 (or NP-40) or buffer (control) before formaldehyde fixation $\left(15 \mathrm{~min}\right.$ at $\left.23^{\circ} \mathrm{C}\right)$ and immunolabeling.

In preparation for immunolabeling, cryosections were blocked for $1 \mathrm{hr}$ at $23^{\circ} \mathrm{C}$ in PBS containing $1 \%$ BSA, $5 \%$ normal serum (goat or donkey), and $0.05 \%$ Triton $\mathrm{X}-100$. Incubations in primary antibodies, appropriately diluted in blocking solution, were performed for $2 \mathrm{hr}$ at $23^{\circ} \mathrm{C}$ or overnight at $4^{\circ} \mathrm{C}$. In double-labeling experiments, sections were incubated successively with antibodies to KIF3A (monoclonal) and a synaptic vesicle marker (polyclonal). Primary antibodies were detected with rhodamine- and fluorescein-labeled secondary antibodies (1:200 dilution; Jackson ImmunoResearch Laboratories, West Grove, PA) (added simultaneously in double-labeling experiments). Control experiments were performed with preimmune IgG fractions or immune IgG fractions adsorbed against the antigen, used at the same $\operatorname{IgG}$ concentration as immune antibodies. To reveal the labeling of the OPL as described under Results, it was essential to perform all incubations with antibodies in the presence of Triton X-100. Fixation with $4 \%$ paraformaldehyde was superior to methanol fixation.

Digital micrographs were taken on a Zeiss Axiophot microscope (Carl Zeiss, Thornwood, NY) equipped with a Sony color CCD video camera, and collected using Northern Exposure image analysis software (Empix Imaging, Mississauga, Ontario, Canada). Images were transferred to Adobe Photoshop and edited for contrast and brightness. Micrographs from control experiments were processed identically.

\section{Ultrastructural immunocytochemistry}

Cryoimmunoelectron microscopy. Rat retina specimens, fixed overnight in PBS containing $4 \%$ paraformaldehyde and $0.1 \%$ glutaraldehyde, were cryoprotected by infiltration with $2.1 \mathrm{M}$ sucrose, $0.2 \mathrm{M}$ glycine in PBS, and frozen in liquid nitrogen. Ultrathin sections were cut at $-120^{\circ} \mathrm{C}$ with a diamond knife and transferred to formvar/carbon-coated copper grids. Immunolabeling was performed with K2.4 antibody diluted up to 1:1000 

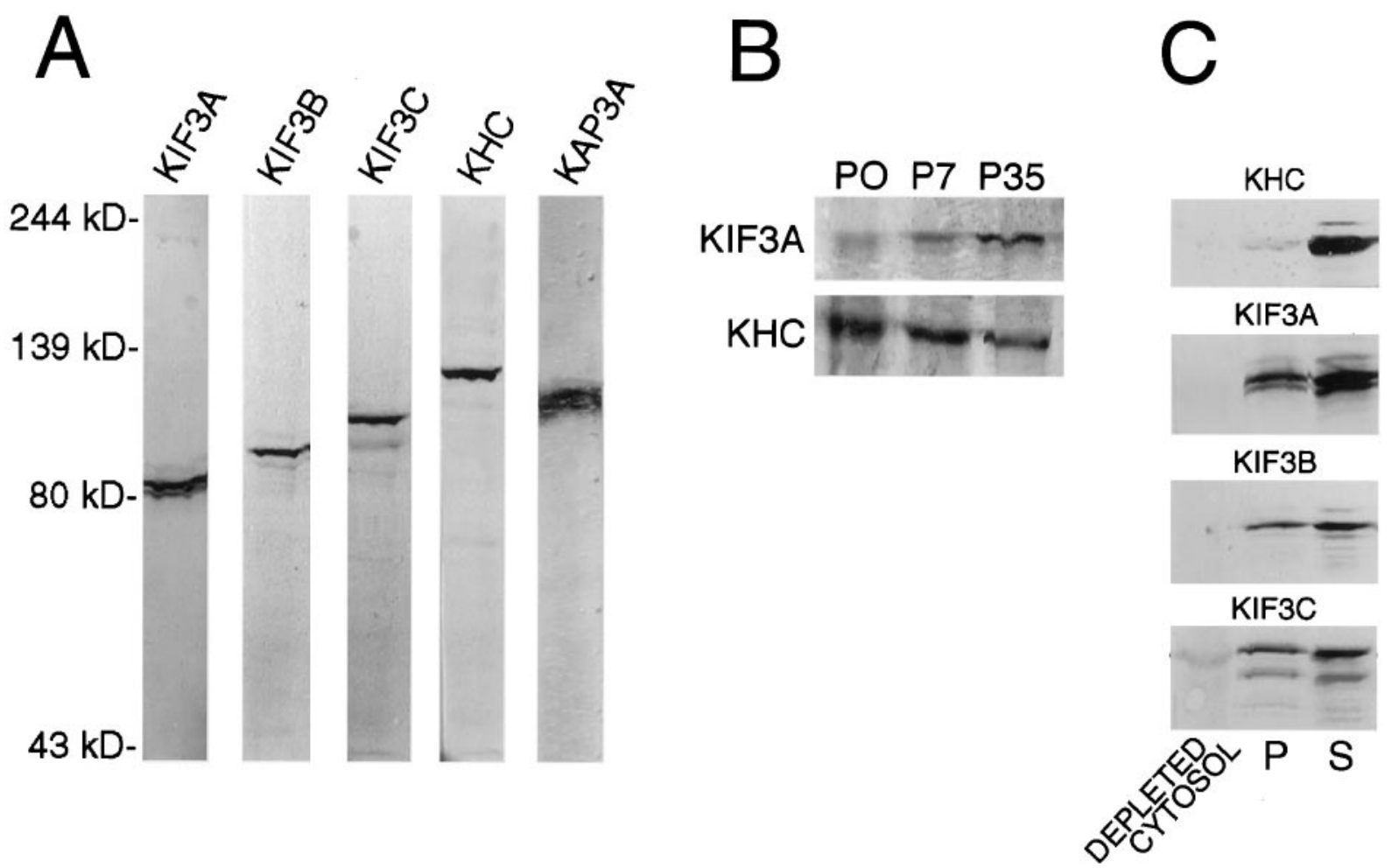

Figure 2. KIF3 motors are expressed in the rat retina. $A$, A retina homogenate from adult animals was analyzed by Western blotting with antibodies to conventional kinesin heavy chain (KHC), KIF3A, KIF3B, KIF3C, and KAP3A. Similar to brain KIF3A (Kondo et al., 1994; Muresan et al., 1998), retinal KIF3A is detected as a doublet, with the upper band being predominant. B, Expression of KIF3A and KHC in neonatal retina. P0, P7, and P35 indicate day 0,7 , and 35 after birth. Note that the level of KIF3A, but not KHC, increases during postnatal development of the retina. $C$, Nucleotide-dependent microtubule binding and release of retinal kinesins. A Triton X-100-solubilized retinal homogenate was incubated with microtubules and AMP-PNP. Microtubules were separated from the depleted cytosol and extracted with ATP and NaCl. Supernatant $(S)$ and pellet $(P)$ of extracted microtubules were obtained by centrifugation.

in the presence of $1 \%$ bovine serum albumin, followed by a bridging rabbit anti-mouse antibody and Protein A-gold (10 nm). Sections were stained with $0.3 \%$ uranyl acetate in $2 \%$ methylcellulose solution.

Postembedding procedure. Fixed rat retina specimens were incubated successively with $1 \%$ tannic acid, $1 \%$ uranyl acetate, then dehydrated, infiltrated in Unicryl (Goldmark Biologicals, Philipsburg, NJ), and polymerized at $40^{\circ} \mathrm{C}$ for $24-48 \mathrm{hr}$. Thin sections were blocked with $1 \%$ bovine serum albumin, $0.1 \%$ Triton $\mathrm{X}-100$, and immunolabeled as described above. Sections were poststained with uranyl acetate and lead citrate. The two immunoelectron microscopy procedures are presumed to differ in the degree of structural preservation of the tissue, antigen preservation, and accessibility of antibodies to various antigens. In our hands, the postembedding procedure allowed for a better detection of vesicular profiles at the photoreceptor synapse.

\section{Antibodies}

The following rabbit polyclonal antibodies were used: anti-KIF3B and anti-KIF3C antibodies (affinity-purified), raised to His-tagged fusion proteins from the $\mathrm{C}$-terminal region of rat KIF3B and the coiled-coil region of rat KIF3C (Muresan et al., 1998); anti-cysteine string protein 1 (CSP1), raised against recombinant CSP1 (Chamberlain and Burgoyne, 1996) (gift of Dr. Robert Burgoyne, University of Liverpool, UK); and MC17 (anti-synaptotagmin; a gift from Dr. Pietro De Camilli, Howard Hughes Medical Institute, Yale University School of Medicine, New Haven, CT). The following mouse monoclonal antibodies were used: K2.4 (ascites fluid), from mice immunized with sea urchin kinesin II (Cole et al., 1993; Henson et al., 1995), detects primarily the $85 \mathrm{kDa}$ component of kinesin II and cross-reacts with a protein doublet corresponding to KIF3A in Western blots of rat brain extract (gift of Dr. Jonathan M. Scholey, University of California at Davis); H2, from mice immunized with bovine brain kinesin heavy chain (Pfister et al., 1989), recognizes the full range of bovine kinesin heavy chain isoforms (Brady et al., 1990) (gift from Dr. George Bloom, University of Texas South Western). The kinesin superfamily-associated protein 3 (KAP3) was detected with a monoclonal antibody to the KAP3A isoform from mouse (Transduction Laboratories, Lexington, KY).

\section{RESULTS}

\section{Differential distribution of kinesin motors in the mammalian retina}

To identify kinesins expressed in the retina, we immunoblotted tissue homogenates with a battery of antibodies against neuronal kinesins (Fig. 2). Rat retina contained polypeptides that crossreacted with antibodies to conventional kinesin heavy chain (KHC) and to the three members of the KIF3 family of kinesin polypeptides (KIF3A, KIF3B, and KIF3C). Each antibody detected primarily one polypeptide, or in the case of KIF3A, a doublet (Kondo et al., 1994; Muresan et al., 1998), that bound to purified microtubules in an AMP-PNP dependent manner and released in an ATP-dependent manner (Fig. 2C), indicative of kinesin-like motor activity (Vale et al., 1985).

Kinesin polypeptides belonging to the KIF3 family are distinguished by their ability to form specific heteromers (Scholey, 1996). Thus, KIF3A (Cole et al., 1992, 1993; Kondo et al., 1994) exists in vivo as a complex with a second kinesin-related polypeptide, either KIF3B (Rashid et al., 1995; Yamazaki et al., 1995) or KIF3C (Muresan et al., 1998; Yang and Goldstein, 1998). The kinesin II holoenzyme (Scholey, 1996) is a trimeric complex between KIF3A, KIF3B, and an associated, nonmotor polypeptide, KAP3 (Wedaman et al., 1996; Yamazaki et al., 1996). As expected, we have found that rat retina also contained KAP3 (Fig. 2A). 


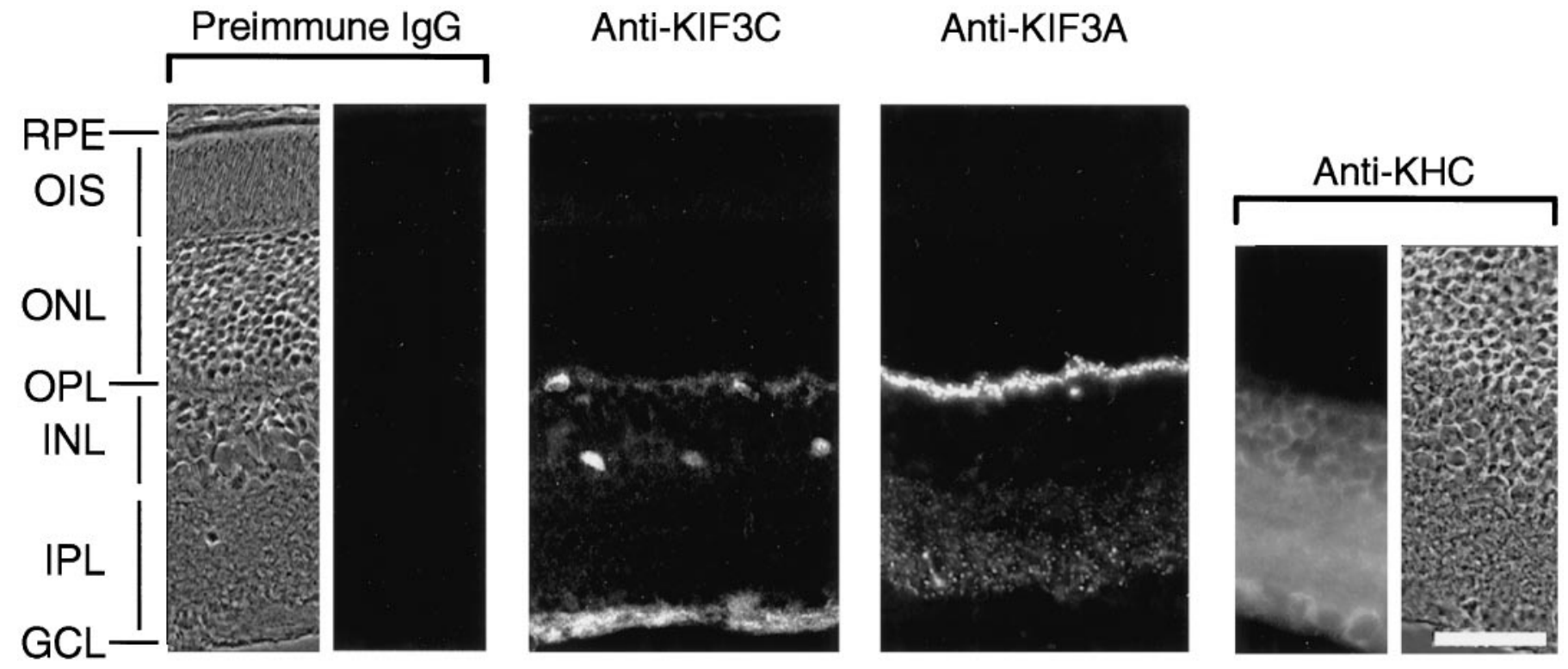

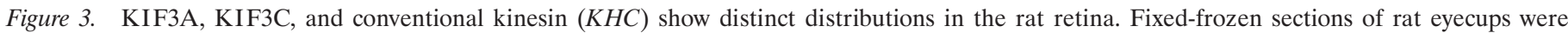

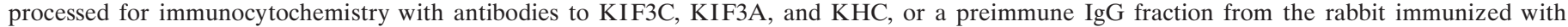

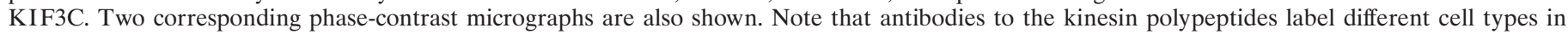

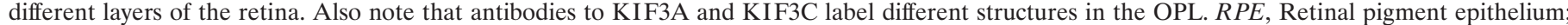

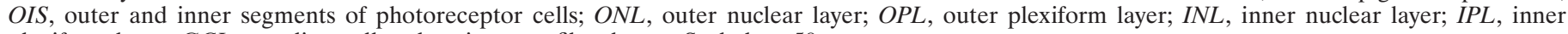
plexiform layer; $G C L$, ganglion cell and optic nerve fiber layers. Scale bar, $50 \mu \mathrm{m}$.

We used the antibodies against $\mathrm{KHC}, \mathrm{KIF} 3 \mathrm{~A}$, and $\mathrm{KIF} 3 \mathrm{C}$ to examine by immunofluorescence microscopy the distribution of these motors in fixed-frozen sections from rat retinas collected during the day. Each antigen was distinctly localized (Fig. 3). $\mathrm{KHC}$ was uniformly distributed throughout the inner retinal layers, consistent with its ubiquitous distribution in most cells (Goodson et al., 1997). As reported previously (Muresan et al., 1998), KIF3C was detected primarily in ganglion cell bodies and axons and in certain amacrine and horizontal cells. Faint, diff use labeling within the OPL was presumably from horizontal cell processes. These findings are consistent with a role of KIF3C in axonal transport. KIF3A showed the most distinct labeling pattern, confined almost exclusively to the two synaptic layers (i.e., OPL and IPL) (Fig. 3). This suggested a role at presynaptic or postsynaptic endings, which we investigated further.

\section{KIF3A is present at ribbon synapses}

To test whether KIF3A was indeed localized to synapses in the inner and outer plexiform layers, we performed double-labeling using antibodies against KIF3A and the synaptic vesicle markers synaptotagmin (Perin et al., 1991) and cysteine string protein 1 (CSP1) (Chamberlain and Burgoyne, 1996). Overlaid images showed that the discrete, punctate KIF3A labeling exists within the boundaries of a uniform labeling that reflects the distribution of the synaptic vesicles in these layers (Fig. 4). This discrete distribution of KIF3A, as opposed to the continuous distribution of the synaptic vesicle markers, suggested that KIF3A was particularly concentrated within a small region of the photoreceptor synaptic terminal in the OPL and within a subset of presynaptic terminals in the IPL.

At higher magnification, the anti-KIF3A-labeled structures in the OPL appeared to have the horseshoe shape (Fig. 5, A, top image, and $B$ ) of the photoreceptor ribbon (Balkema, 1991), which arches between two protruding horizontal cell processes, directly above one or two bipolar cell processes (Fig. 5C) (also see
Rao-Mirotznik et al., 1995). In the IPL, KIF3A labeling appeared as dots increasing in size toward the innermost portion of the labeled region (Fig. $5 \mathrm{~A}$, bottom image). Here, the distribution and shape of the anti-KIF3A-labeled structures were indicative of the smaller, punctate synaptic ribbons (Balkema, 1991) made by bipolar cells with amacrine and ganglion cells (Dowling and Boycott, 1966). A similar distribution of KIF3A was observed in the retinas from other vertebrate species including mouse, bovine, frog, and chicken (data not shown). We conclude that KIF3A is localized to the ribbon synapses of the retina in numerous vertebrate species.

\section{KIF3A is a component of the presynaptic ribbon in photoreceptors}

The ribbon is a proteinaceous, electron-dense plate, situated within the presynaptic terminal (Sjöstrand, 1953) where the presynaptic vesicles are docked (Gray and Pease, 1971; Raviola and Gilula, 1975; Rao-Mirotznik, 1995). The functional importance of this striking synaptic specialization to the transduction and processing of sensory stimuli is unclear, as is its biochemical composition.

To identify in more detail the relationship between KIF3A and the photoreceptor ribbon, KIF3A was localized by immunoelectron microscopy using colloidal gold (Fig. 6). The micrographs indicate that KIF3A is concentrated on many, but not all, of the vesicles attached to and in the vicinity of the ribbon. This is consistent with the immunofluorescence observations (Fig. 4), which suggested that not all vesicles at the synaptic terminal contain KIF3A.

In addition to labeling vesicles, gold particles also decorated the ribbon matrix, suggesting that KIF3A might be an integral component of the ribbon itself (Fig. 6C,D). Because ribbons are resistant to extraction with nonionic detergents (Schmitz et al., 1996), we tested the detergent solubility of KIF3A compared with known vesicle proteins. Immunofluorescence microscopy of reti- 


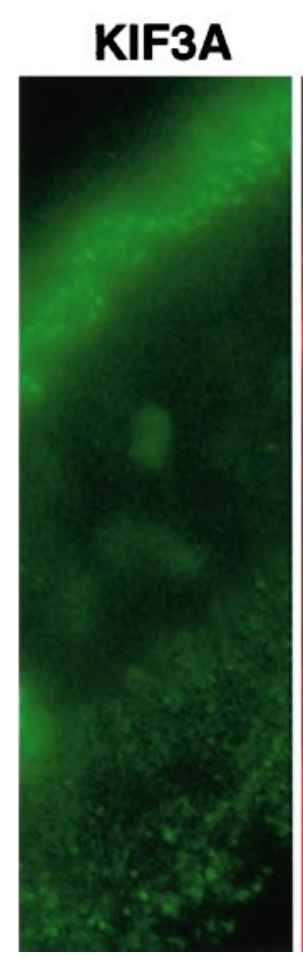

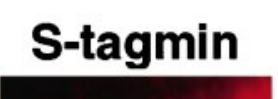
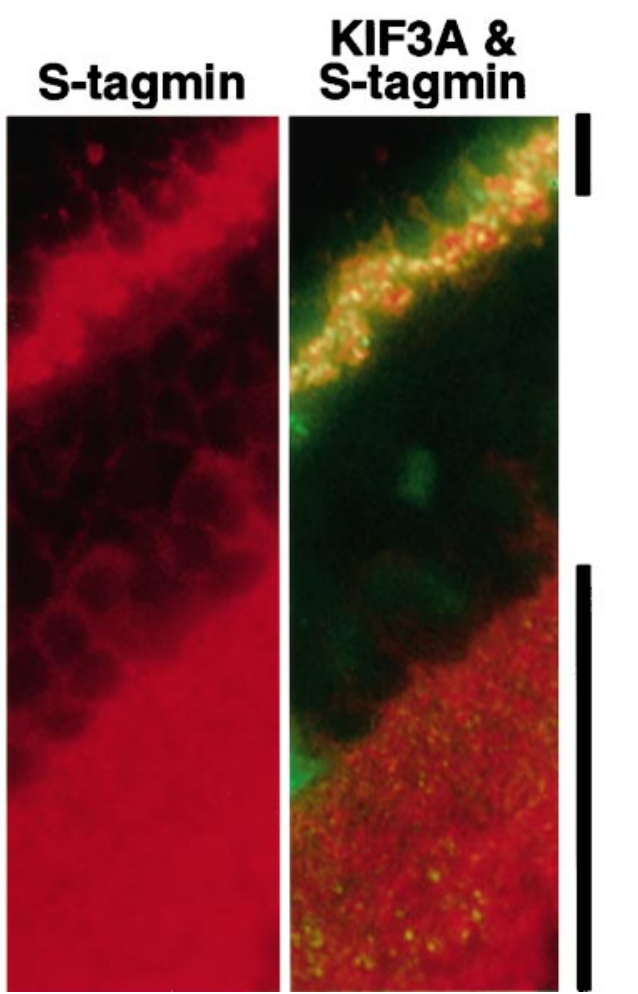

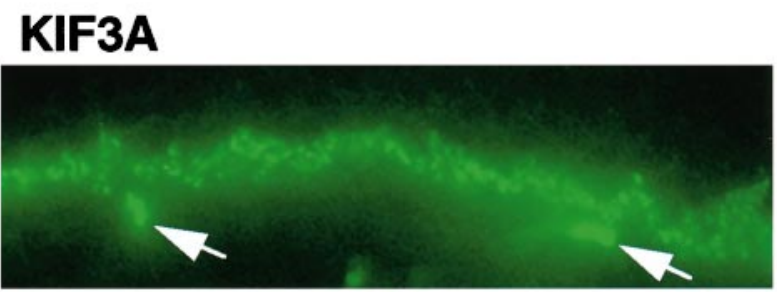

\section{CSP1}

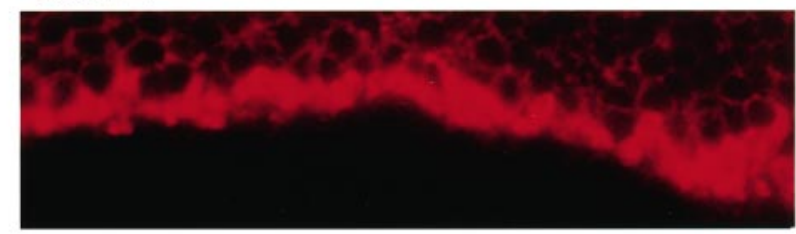

\section{KIF3A \& CSP1}

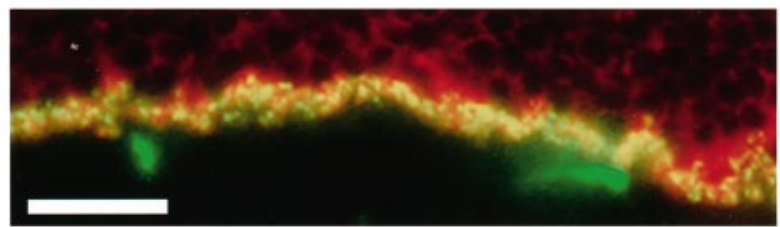

Figure 4. The distribution of KIF3A is included within the distribution of synaptic vesicle markers. Fixed-frozen sections through rat retina were double-stained with anti-KIF3A antibody and either synaptotagmin $(A)$ or CSP1 $(B)$. KIF3A was detected with fluorescein isothiocyanate-labeled secondary antibodies (green), whereas rhodamine-labeled secondary antibodies (red) were used to detect the synaptic vesicle markers. The merged images were obtained by simultaneous visualization of both fluorophores through a broad-band filter. Note the discrete distribution of KIF3A as opposed to the continuous distribution of the synaptic vesicle markers. The fluorescein isothiocyanate-labeled secondary (anti-mouse IgG) antibody used in these experiments cross-reacts with rat IgG and labels capillaries (arrows, B). Only the OPL is shown in B. Scale bar, $20 \mu \mathrm{m}$.

nal sections extracted with Triton X-100 or NP-40 before fixation showed that KIF3A immunoreactivity was largely resistant to detergent extraction (Fig. 7A,B). By contrast, the vesicle membrane-associated protein CSP1 was completely extracted with nonionic detergent. Subcellular fractionation experiments confirmed these results. When a crude synaptic membrane fraction prepared from a low-speed retinal supernatant was extracted with Triton X-100, approximately half of KIF3A co-sedimented with the detergent-insoluble pellet. CSP1, by contrast, was recovered entirely in the supernatant (Fig. 7C). These results suggest that a fraction of KIF3A is firmly bound to the ribbon matrix.

\section{KIF3A is concentrated at the photoreceptor basal body and connecting cilium axoneme}

In addition to its localization within the plexiform layers, KIF3A was detected in the inner segment and near the basal body of the photoreceptor connecting cilium. This labeling was particularly clear in tissue sections extracted with Triton X-100 before fixation and appeared as fluorescent dots (Fig. 8A). These dots were at the base of the axonemes, because they colocalized with an antibody against $\gamma$-tubulin (data not shown), which was previously shown to reside in this location (Muresan et al., 1993). Because KIF3A is present as a component of the kinesin II holoenzyme at the analogous location in Chlamydomonas flagella (Cole et al., 1998), we asked whether the other kinesin II polypeptides, KIF3B and KAP3, were also present at the basal body of the photoreceptor connecting cilium axoneme.
KIF3B and KAP3 were not detected by immunofluorescence, possibly because the antibodies were not sufficiently sensitive. We therefore asked whether immunoblotting could detect KIF3A, $\mathrm{KIF} 3 \mathrm{~B}$, and KAP3 in a subcellular fraction enriched in bovine photoreceptor axonemes (Muresan and Besharse, 1994; Muresan et al., 1997). All three polypeptides were apparent in immunoblots of these fractions (Fig. 8D). By contrast, KIF3C, which is not a component of kinesin II, was not apparent. These findings suggest that the kinesin II holoenzyme, composed of KIF3A, KIF3B, and KAP3, and present at conventional cilia and flagella, is also associated with the photoreceptor axoneme.

We have investigated the expression of KIF3A during postnatal development of the rat retina. The level of KIF3A increased throughout these stages of development (Fig. 2B), whereas that of KHC (Fig. 2B) and KIF3C (data not shown) remained relatively constant. The pattern of expression of these motor proteins, as shown by Western blotting, correlates well with the development of the retinal layers to which they are confined (Fig. 3). Thus, the time course of expression of KIF3A, which is localized to the ribbon synapses of photoreceptors and bipolar cells as well as to photoreceptor axonemes, closely parallels the time course of synaptogenesis in the photoreceptor and bipolar cell terminals and the development of photoreceptor outer segments (Braekevelt and Hollenberg, 1970; McArdle et al., 1977; Hermes et al., 1992; Bachman and Balkema, 1993). By contrast, the constant level of expression of KIF3C and KHC likely reflects 


\section{A}
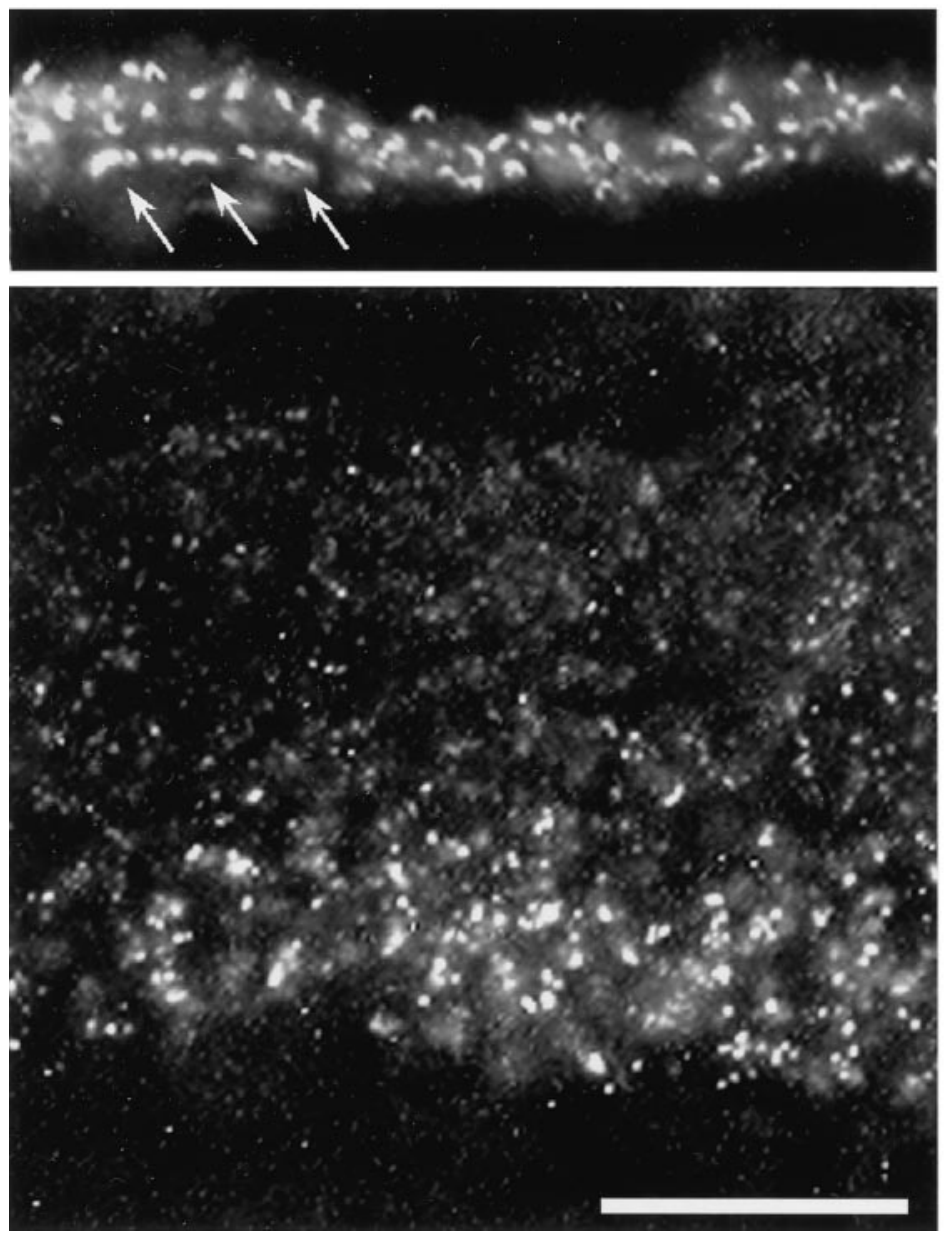
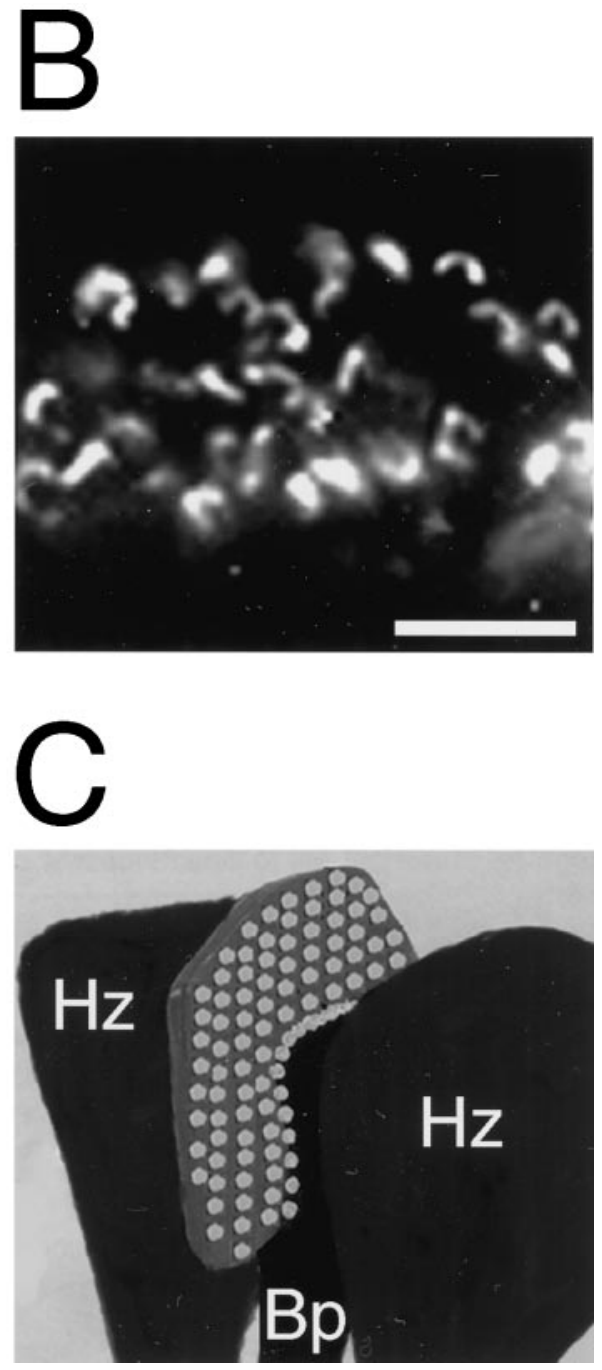

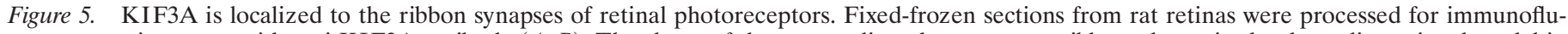

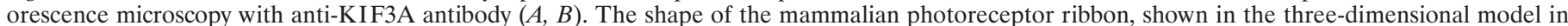

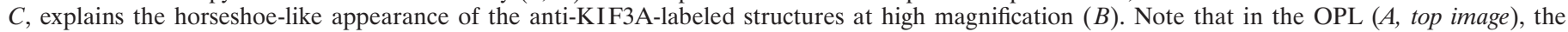

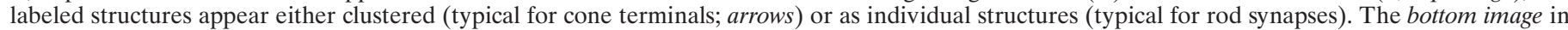

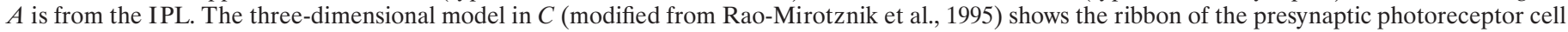
with the docked vesicles and the postsynaptic horizontal $(H z)$ and bipolar $(B p)$ cells. Scale bars: $A, 25 \mu \mathrm{m} ; B, 5 \mu \mathrm{m}$.

their localization to inner retinal layers (including the ganglion cell layer) already developed at birth.

\section{DISCUSSION}

To gain insight into the in vivo functions and cargoes of neuronal kinesins, we have used immunocytochemistry and subcellular fractionation, methods that have helped elucidate the function of kinesin motors in mitotic cells (Nislow et al., 1992; Sawin et al., 1992; Yen et al., 1992; Afshar et al., 1995; Vernos et al., 1995). We show that the kinesin polypeptide KIF3A is localized to the presynaptic ribbon and to the basal body of the connecting cilium axoneme in photoreceptor cells. This precise localization of KIF3A to opposite ends of photoreceptors suggests that this kinesin-related polypeptide has two different functions in the same cell.

\section{KIF3A at ribbon synapses}

The presence of KIF3A at presynaptic ribbons within multiple cell types in the retina, including rods, cones, and bipolar cells, and in several species, implies that this motor may have a general role in the function of the ribbon synapse. Examination of other cells with presynaptic ribbons, e.g., pinealocytes (Hopsu and Arstila, 1964) and mechanoreceptive hair cells of auditory, vestibular (Flock, 1964), and lateral-line sensory organs would be required to confirm this conclusion.

Several lines of evidence suggest that KIF3A is restricted to ribbon synapses and is not present at conventional synapses. The majority of synapses in the IPL are conventional and distributed throughout this synaptic layer, as reflected by the wide, uniform distribution of synaptic vesicle markers [Ulrich and Südhof (1994); see also Fig. 4]. KIF3A, however, is localized in a highly restricted manner to punctate structures within the IPL. These are likely to correspond to the small synaptic ribbons within rod bipolar axon terminals (Dowling and Boycott, 1966), which increase in size toward the inner region of the IPL (Kolb, 1979). The apparent lack of KIF3A staining at conventional synapses in the retina is also consistent with previous studies in which KIF3A 


\section{Postembedding EM}
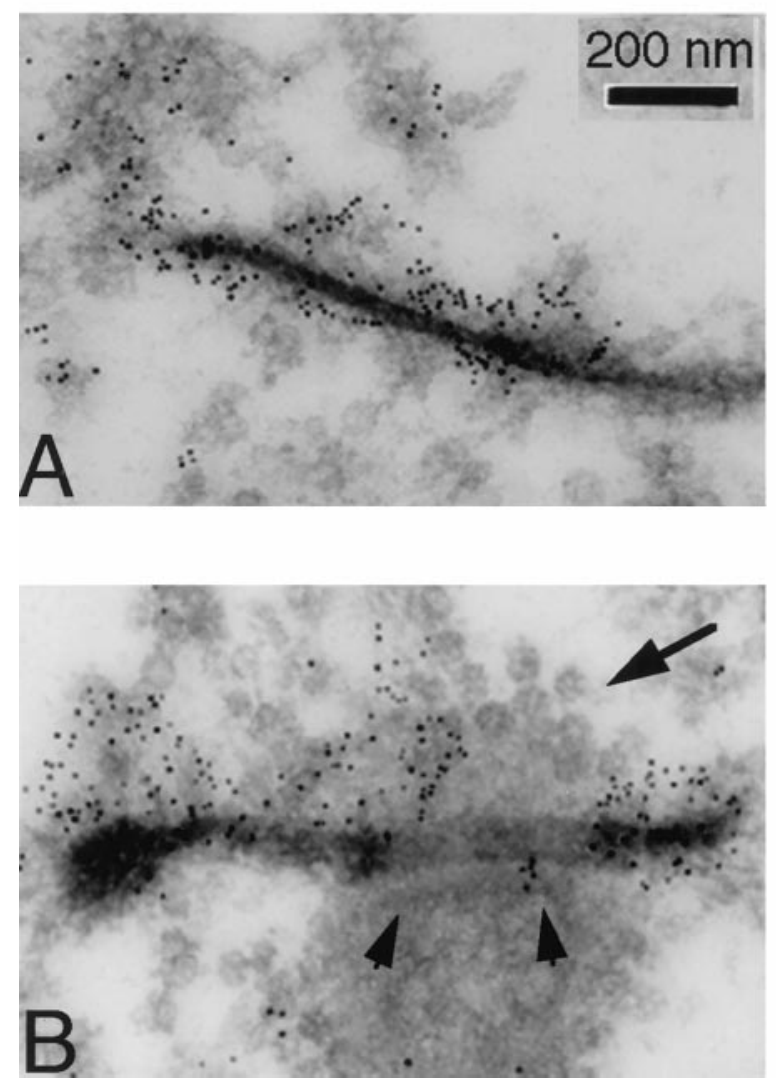

\section{Cryo-immuno EM}
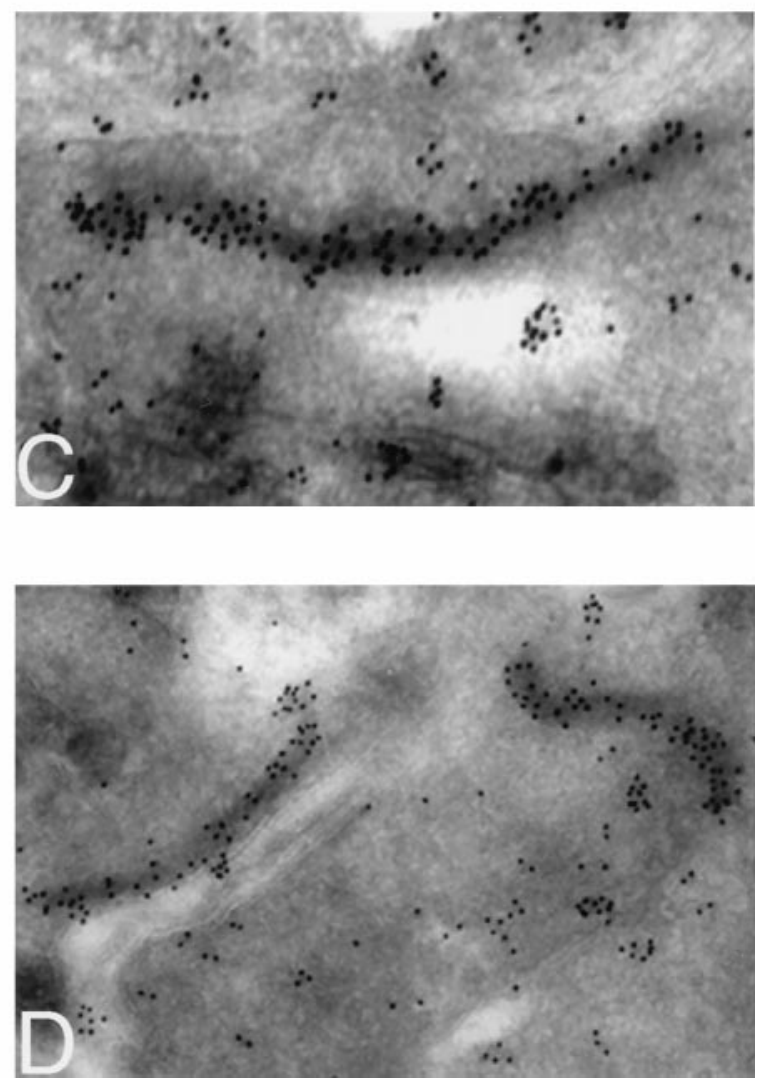

Figure 6. KIF3A is detected at the synaptic ribbon of photoreceptor synapses. Transmission electron micrographs from rat retinal specimens processed for postembedding immunocytochemistry $(A, B)$ or cryoimmunoelectron microscopy $(C, D)$ with anti-KIF3A antibodies. Gold particles are localized to vesicular organelles associated with the synaptic ribbons and scattered throughout the cytoplasm. The highest labeling density is detected over and around the ribbons themselves. Numerous vesicles at the synaptic terminal are unlabeled (B, arrow). The plane of section in $B$ traverses both the presynaptic photoreceptor cell and the postsynaptic horizontal or bipolar cell. Arrowheads show the postsynaptic membrane.

was observed primarily within neuronal cell bodies and axons (Kondo et al., 1994; Muresan et al., 1998) but not within nerve terminals (Muresan et al., 1998). However, it cannot be ruled out that KIF3A is also present at conventional synapses, because their relatively smaller active zones and numbers of docked vesicles compared with ribbon synapses may render an analogous localization undetectable.

The apparently specific localization of KIF3A to ribbon synapses implies some function unique to these synapses. Although ribbon and conventional synapses use similar machinery for docking, fusion, and recycling of synaptic vesicles (Mandell et al., 1990; Ulrich and Südhof, 1994; Brandstatter et al., 1996; Grabs et al., 1996; Morgans et al., 1996), they differ in their structure and physiology (Gray and Pease, 1971; Schaeffer and Raviola, 1978; Dowling, 1987; Redburn, 1988; Burns and Augustine, 1995). In a conventional synapse, synaptic vesicles are docked at the plasma membrane of the active zone, where exocytosis occurs. In ribbon synapses many of the vesicles are a distance away from the active zone, tethered to an electron-dense plate (Raviola and Gilula, 1975; Rao-Mirotznik et al., 1995). Physiologically, ribbon synapses release neurotransmitter continuously, in a graded manner, reflecting the graded membrane potential changes produced by sensory transduction. This is in sharp contrast to conventional synapses, which respond to bursts of all-or-none action potentials (Dowling, 1987; Lagnado et al., 1996). It has been proposed that the ribbon somehow allows for continuous calcium-dependent exocytosis (Ulrich and Südhof, 1994; Burns and Augustine, 1995), an idea that is consistent with the presence of a large pool of rapidly releasable vesicles (von Gersdorff and Matthews, 1994; Rao-Mirotznik et al., 1995; Matthews, 1996) compared with conventional synapses. It has also been proposed that the ribbon allows for simultaneous activation of the two or more postsynaptic cell processes that are typically engaged by a single presynaptic terminal at these synapses (Raviola and Gilula, 1975; Schaeffer et al., 1982; for review, see Sjöstrand, 1998).

Because the actual role of the synaptic ribbon in docking and mobilizing synaptic vesicles for exocytosis is still controversial, it is difficult to define a role for KIF3A based solely on its localization. One possibility is that KIF3A might transport a synaptic vesicle precursor from the Golgi to the terminal, consistent with the function of KIF3A as a plus-end motor (Kondo et al., 1994). This could explain the presence of KIF3A on vesicular profiles in the vicinity of the ribbon but raises the question of why such putative precursor vesicles were not detected in transit from the Golgi. One possibility is that such vesicles, each carrying but a few motors, become detectable only when large numbers are aggregated in one place, as at the ribbon. It is also possible that the total numbers of vesicles in transit at any one time may be small.

At present, it is difficult to assess whether all or only a fraction of the vesicles at the ribbon carry KIF3A, although we have 

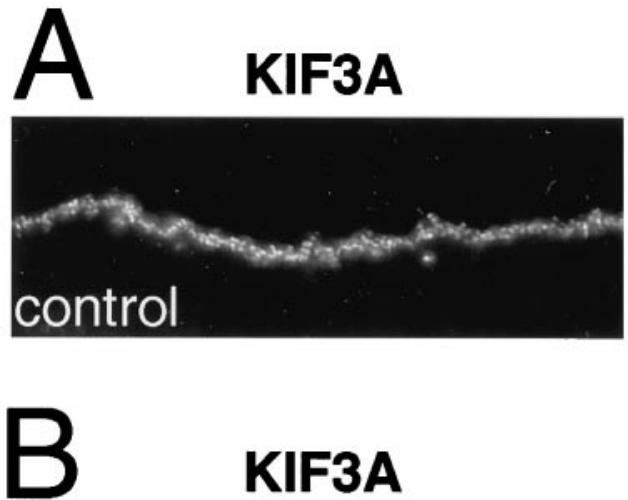

KIF3A
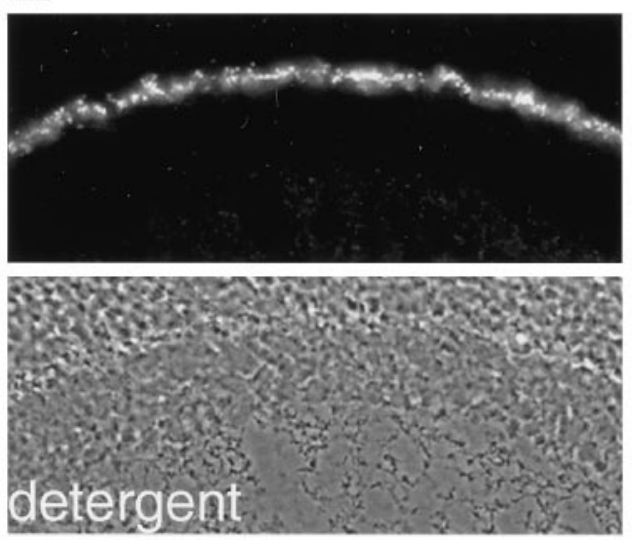

\section{CSP1}

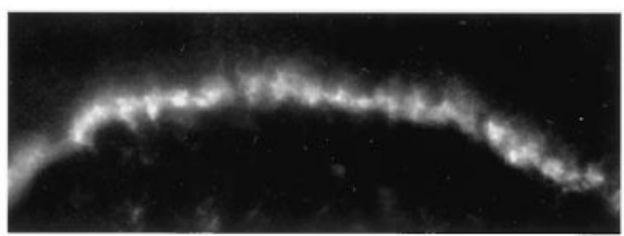

CSP1
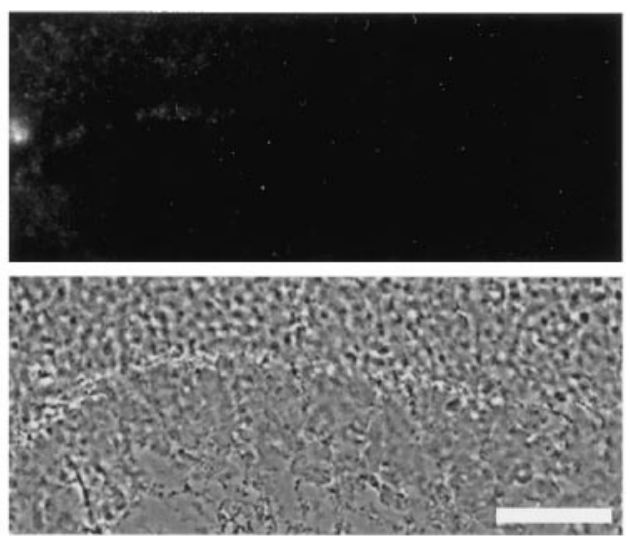

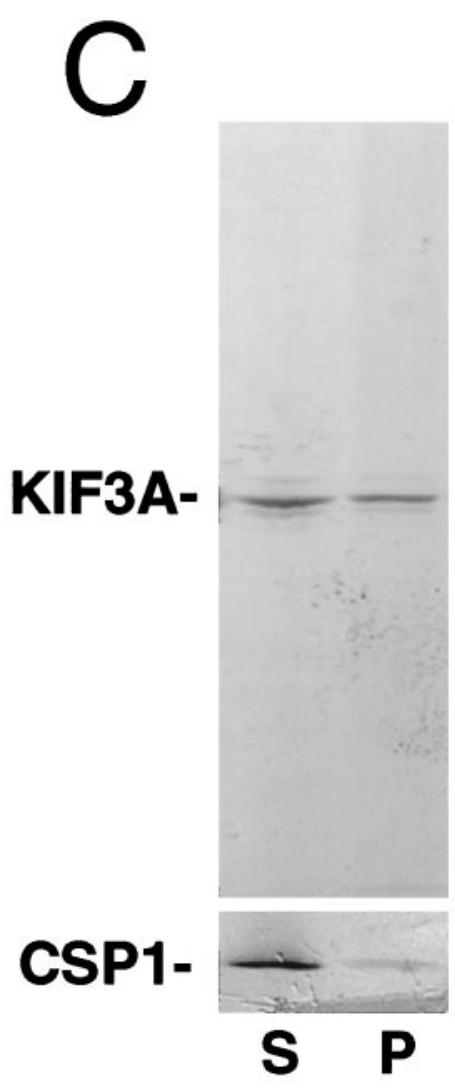

Figure 7. Detergent-soluble and insoluble fractions of KIF3A. $A, B$, Rat retina immunocytochemistry. Fresh-frozen sections were extracted with Triton X-100 $(B)$ or buffer $(A$, control $)$ before formaldehyde fixation and staining with antibodies to KIF3A and CSP1. Bottom images in $B$ are corresponding phase-contrast micrographs. Scale bar, $50 \mu \mathrm{m}$. $C$, Subcellular fractionation of rat retina. A crude rat retina synaptic membrane fraction was extracted with Triton X-100. After centrifugation, the supernatant $(S)$ and pellet $(P)$ were analyzed by Western blotting with antibodies to KIF3A and CSP1.

consistently noticed groups of unlabeled vesicles at or in the vicinity of the ribbon (Fig. 6A,B). On the basis of capacitance measurements from the presynaptic terminals of the giant ribbon synapse in the goldfish retina (von Gersdorff and Matthews, 1994; Matthews, 1996), three pools of vesicles could be distinguished physiologically by the rapidity with which they fuse with the plasma membrane after stimulation. These include a rapidrelease pool docked at the ribbon, a reserve pool that can replenish the rapidly released pool, and a reservoir of vesicles available to refill the reserve pool (Matthews, 1966; von Gersdorff and Matthews, 1997). Of these, it seems unlikely that KIF3A would serve to carry vesicles already docked on the ribbon to the active zone where exocytosis occurs, because microtubules are absent from the region between the ribbon and the active zone.

In addition to its association with the docked vesicles, KIF3A is also localized to the ribbon matrix itself, as indicated by the electron microscopy and detergent extraction experiments. This sizable, ribbon-associated, detergent-insoluble fraction of KIF3A could reflect a sorting process in which the motor is removed from vesicles when they are delivered to the ribbon by microtubulebased transport. Alternatively, it is possible that KIF3A participates in the transport of components of the ribbon matrix itself.

\section{The dual function of KIF3A in photoreceptors}

It is apparent that KIF3A must have at least two distinct functions in photoreceptors (Fig. 1). In addition to its presence at the synaptic ribbon, KIF3A is also present at the basal body and the proximal region of the connecting cilium axoneme. This is con- sistent with biochemical data showing that a fraction of retinal KIF3A is present in photoreceptor inner and outer segments (Fig. $8 C$ ) and with previous reports of KIF3A at this location in fish photoreceptor cells (Beech et al., 1996). In addition, we show that not only KIF3A but also KIF3B and KAP3, i.e., the other two polypeptides of the kinesin II holoenzyme, are present in isolated photoreceptor axonemes. We therefore suggest that KIF3A in this part of the cell is a component of the kinesin II holoenzyme. By analogy with its proposed role in the maintenance and generation of cilia in sea urchin (Morris and Scholey, 1997) and Caenorhabditis elegans (Tabish et al., 1995), and of flagella in Chlamydomonas (Cole et al., 1998), we suggest that in photoreceptors this motor complex transports material (e.g., components of the phototransduction machinery) from the base of the connecting cilium along the connecting cilium axoneme to the outer segment. Still, it remains to be established how this material is transported from the site of synthesis in the cell body and proximal inner segment to the periciliary region (Besharse, 1986). According to the polarity of microtubules in this region of the photoreceptor cell (Muresan et al., 1993; Troutt and Burnside, 1988) (Fig. 1), it is likely that minus-end-directed motors are involved. By the same argument, the KIF3A motor itself probably reaches the connecting cilium region in an inactive form, where it becomes activated by a still unknown mechanism.

It is now important to ask what are the other polypeptides that interact with KIF3A at the synaptic ribbon, because this should provide clues regarding the mechanism by which these two trans- 

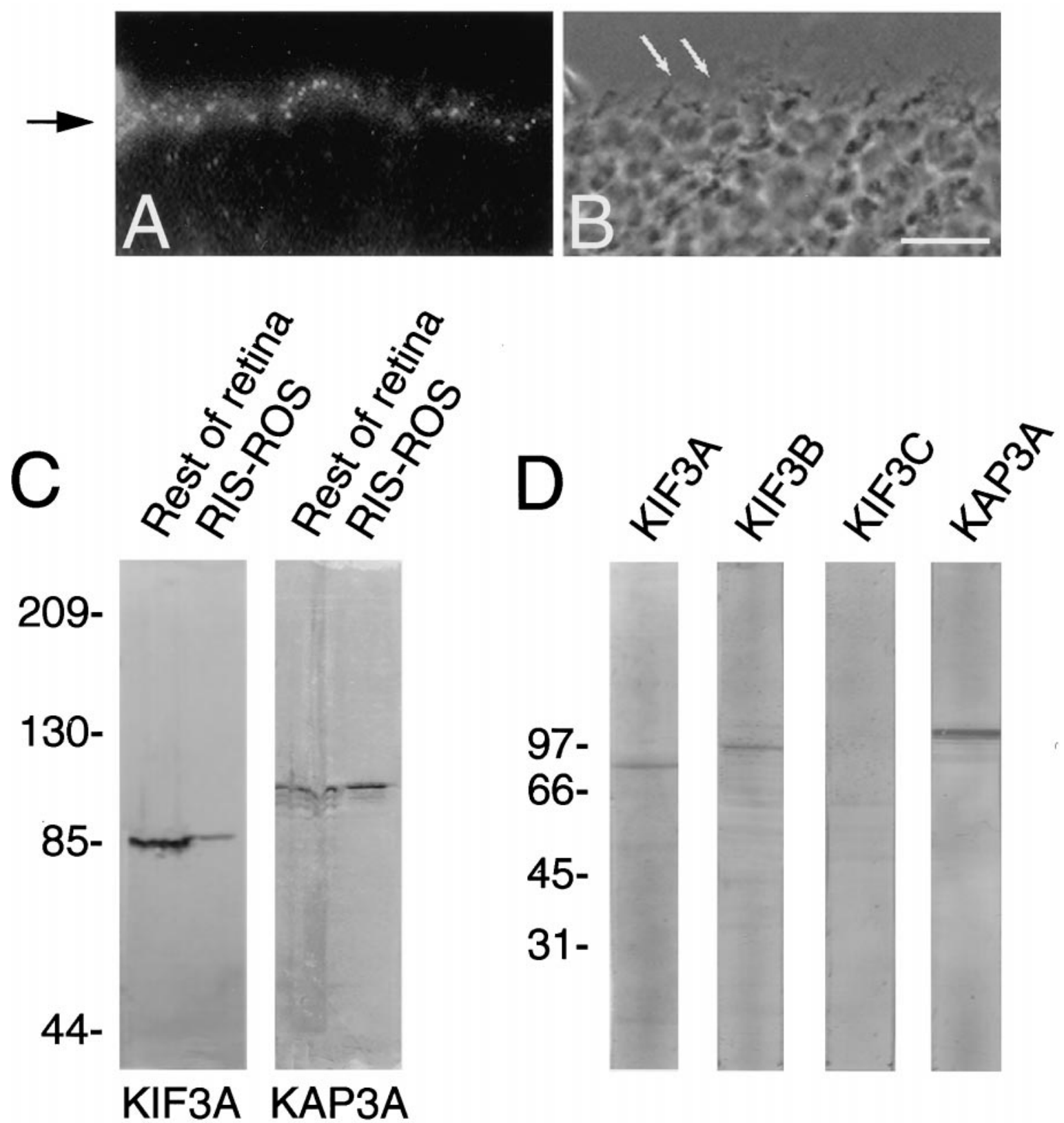

Figure 8. KIF3A is localized to the photoreceptor axoneme. $A, B$, Rat retina immunocytochemistry. Fresh-frozen sections were extracted with Triton $\mathrm{X}-100$, fixed with formaldehyde, and stained with anti-KIF3A antibody. Note that photoreceptor outer segments have been solubilized by detergent extraction. Some extracted axonemes are indicated by arrows $(B)$. The location of the labeled dots in $A$ corresponds to the base of the axonemes (black arrow). $B$ is a phase-contrast micrograph corresponding to $A$. Scale bar, $20 \mu \mathrm{m}$. $C$, Rod inner and outer segments (RIS-ROS) contain KIF3A and KAP3A. RIS-ROS were prepared from rat retina and analyzed by Western blotting. $D$, Western blotting of a bovine photoreceptor axoneme fraction with antibodies to KIF3A, KIF3B, KIF3C, and KAP3A.

port pathways are regulated. KIF3A is known to exist in at least two distinct heteromeric complexes, one with KIF3B and KAP3 as part of the kinesin II holoenzyme (Scholey, 1996), the other in an as yet poorly defined complex with a related kinesin polypeptide, KIF3C (Muresan et al., 1998; Yang and Goldstein, 1998). The lack of KIF3C and KIF3B labeling of presynaptic ribbons, combined with the relative enrichment of the accessory subunit KAP3 in photoreceptor inner and outer segments, i.e., outside the synaptic terminal (Fig. $8 C$ ), raises the possibility that KIF3A in association with the ribbon represents a distinct form of KIF3A. It is likely that the direct purification of this holoenzyme from isolated synaptic ribbons (Schmitz et al., 1996) will provide important clues regarding the nature of this motor and the function of ribbon synapses.

\section{REFERENCES}

Afshar K, Barton NR, Hawley RS, Goldstein LSB (1995) DNA binding and meiotic chromosomal localization of the Drosophila nod kinesinlike protein. Cell 81:129-138.

Bachman KM, Balkema GW (1993) Developmental expression of a synaptic ribbon antigen (B16) in mouse retina. J Comp Neurol 333:109-117.

Balkema GW (1991) A synaptic antigen (B16) is localized in retinal synaptic ribbons. J Comp Neurol 312:573-583.

Barthel LK, Raymond PA (1990) Improved method for obtaining 3- $\mu \mathrm{m}$ 
cryosections for immunocytochemistry. J Histochem Cytochem 38:1383-1388.

Beech PL, Pagh-Roehl K, Noda Y, Hirokawa N, Burnside B, Rosenbaum JL (1996) Localization of kinesin superfamily proteins to the connecting cilium of fish photoreceptors. J Cell Sci 109:889-897.

Besharse JC (1982) The daily light-dark cycle and rhythmic metabolism in the photoreceptor-pigment epithelial complex. Prog Ret Res $1: 81-124$

Besharse JC (1986) Photosensitive membrane turnover: differentiated membrane domains and cell-cell interactions. In: The retina: a model for cell biological studies, Part I (Adler R, Farber D, eds), pp 297-352. New York: Academic

Besharse JC, Horst CJ (1990) The photoreceptor connecting cilium. A model for the transition zone. In: Ciliary and flagellar membranes (Bloodgood RA, ed), pp 389-417. New York: Plenum.

Brady ST, Pfister KK, Bloom GS (1990) A monoclonal antibody against kinesin inhibits both anterograde and retrograde fast axonal transport in squid axoplasm. Proc Natl Acad Sci USA 87:1061-1065.

Braekevelt CR, Hollenberg M (1970) The development of the retina of the albino rat. Am J Anat 127:281-301.

Brandstatter JH, Wassle H, Betz H, Morgans CW (1996) The plasma membrane protein SNAP-25, but not syntaxin, is present at photoreceptor and bipolar cell synapses in the rat retina. Eur $\mathrm{J}$ Neurosci 8:823-828

Burns ME, Augustine GJ (1995) Synaptic structure and function: dynamic organization yields architectural precision. Cell 83:187-194.

Chamberlain LH, Burgoyne RD (1996) Identification of a novel cysteine string protein variant and expression of cysteine string proteins in non-neuronal cells. J Biol Chem 271:7320-7323.

Cole DG, Cande WZ, Baskin RJ, Skoufias DA, Hogan CJ, Scholey JM (1992) Isolation of sea urchin egg kinesin-related protein using peptide antibodies. J Cell Sci 101:291-301.

Cole DG, Chinn SW, Wedaman KP, Hall K, Vuong T, Scholey JM (1993) Novel heterotrimeric kinesin-related protein purified from sea urchin eggs. Nature (Lond) 366:268-270.

Cole DG, Diener DR, Himelblau AL, Beech PL, Fuster JC, Rosenbaum JL (1998) Chlamydomonas kinesin-II-dependent intraflagellar transport (IFT): IFT particles contain proteins required for ciliary assembly in Caenorhabditis elegans sensory neurons. J Cell Biol 141:993-1008.

Coy DL, Howard J (1994) Organelle transport and sorting in axons. Curr Opin Neurobiol 4:662-667.

Dowling JE (1987) The retina: an approachable part of the brain. Cambridge, MA: Harvard UP.

Dowling JE, Boycott BB (1966) Organization of the primate retina: electron microscopy. Proc R Soc Lond B Biol Sci 166:80-111.

Flock A (1964) Structure of the macula utriculi with special reference to directional interplay of sensory responses as revealed by morphological polarization. J Cell Biol 22:413-431.

Goodson HV, Valetti C, Kreis TE (1997) Motors and membrane traffic. Curr Opin Cell Biol 9:18-28.

Grabs D, Bergmann M, Urban M, Post A, Gratzl M (1996) Rab3 proteins and SNAP-25, essential components of the exocytosis machinery in conventional synapses, are absent from ribbon synapses of the mouse retina. Eur J Neurosci 8:162-168.

Gray EG, Pease HL (1971) On understanding the organization of the retinal receptor synapses. Brain Res 35:1-15.

Henson JH, Cole DG, Terasaki M, Rashid D, Scholey JM (1995) Immunolocalization of the heterotrimeric kinesin-related protein $\mathrm{KRP}_{85}$ 95 ) in the mitotic apparatus of sea urchin embryos. Dev Biol 171:182-194.

Henson JH, Cole DG, Roesener CD, Capuano S, Mendola RJ, Scholey JM (1997) The heterotrimeric motor protein kinesin-II localizes to the midpiece and flagellum of sea urchin and sand dollar sperm. Cell Motil Cytoskeleton 38:29-37.

Hermes B, Reuss S, Vollrath L (1992) Synaptic ribbons, spheres and intermediate structures in the developing retina. Int J Dev Neurosci $10: 215-223$

Hirokawa N (1998) Kinesin and dynein superfamily proteins and the mechanism of organelle transport. Science 279:519-526.

Hopsu VK, Arstila AU (1964) An apparent somato-somatic synaptic structure in the pineal gland of the rat. Exp Cell Res 37:484-487.

Kolb H (1979) The inner plexiform layer in the retina of the cat: electron microscopic observations. J Neurocytol 8:295-329.

Kondo S, Sato-Yoshitake R, Noda Y, Aizawa H, Nakata T, Matsuura Y,
Hirokawa N (1994) KIF3A is a new microtubule-based anterograde motor in the nerve axon. J Cell Biol 125:1095-1107.

Kozminski KG, Beech PL, Rosenbaum JL (1995) The Chlamydomonas kinesin-like protein FLA10 is involved in motility associated with the flagellar membrane. J Cell Biol 131:1517-1527.

Lagnado L, Gomis A, Job C (1996) Continuous vesicle cycling in the synaptic terminal of retinal bipolar cells. Neuron 17:957-967.

Mandell JW, Townes-Anderson E, Czernik AJ, Cameron R, Greengard P, De Camilli P (1990) Synapsins in the vertebrate retina: absence from ribbon synapses and heterogeneous distribution among conventional synapses. Neuron 5:19-33.

Matthews G (1996) Synaptic exocytosis and endocytosis: capacitance measurements. Curr Opin Neurobiol 6:358-364.

McArdle CB, Dowling JE, Masland RH (1977) Development of outer segments and synapses in the rabbit retina. J Comp Neuro $175: 253-274$.

Morgans CW, Brandstatter JH, Kellerman J, Betz H, Wassle H (1996) A SNARE complex containing syntaxin 3 is present in ribbon synapses of the retina. J Neurosci 16:6713-6721.

Morris RL, Scholey JM (1997) Heterotrimeric kinesin-II is required for the assembly of motile $9+2$ ciliary axonemes on sea urchin embryos. J Cell Biol 138:1009-1022.

Muresan V, Besharse JC (1994) Complex intermolecular interactions maintain a stable linkage between the photoreceptor connecting cilium axoneme and plasma membrane. Cell Motil Cytoskeleton 28:213-230.

Muresan V, Joshi HC, Besharse JC (1993) $\gamma$-Tubulin in differentiated cell types: localization in the vicinity of basal bodies in retinal photoreceptors and ciliated epithelia. J Cell Sci 104:1229-1237.

Muresan V, Godek CP, Reese TS, Schnapp BJ (1996) Plus-end motors override minus-end motors during transport of squid axon vesicles on microtubules. J Cell Biol 135:383-397.

Muresan V, Bendala-Tufanisco E, Hollander BA, Besharse JC (1997) Evidence for kinesin-related proteins associated with the axoneme of retinal photoreceptors. Exp Eye Res 64:895-903.

Muresan V, Abramson T, Lyass A, Winter D, Porro E, Hong F, Chamberlin NL, Schnapp BJ (1998) KIF3C and KIF3A form a novel neuronal heteromeric kinesin that associates with membrane vesicles. Mol Biol Cell 9:637-652.

Nakagawa T, Tanaka Y, Matsuoka E, Kondo S, Okada Y, Noda Y, Kanai Y, Hirokawa N (1997) Identification and classification of 16 new kinesin superfamily (KIF) proteins in mouse genome. Proc Natl Acad Sci USA 94:9654-9659.

Nislow C, Lombillo VA, Kuriyama R, McIntosh JR (1992) A plus-enddirected motor enzyme that moves antiparallel microtubules in vitro localizes to the interzone of mitotic spindles. Nature 359:543-547.

Perin MS, Johnston PA, Ozcelik T, Jahn R, Francke U, Südhof TC (1991) Structural and functional conservation of synaptotagmin (p65) in Drosophila and humans. J Biol Chem 266:615-622.

Perkins LA, Hedgecock EM, Thomson JN, Culotti JG (1986) Mutant sensory cilia in the nematode Caenorhabditis elegans. Dev Biol 117:456-487

Pfister KK, Wagner MC, Stenoien DA, Brady ST, Bloom GS (1989) Monoclonal antibodies to kinesin heavy and light chains stain vesiclelike structures, but not microtubules, in cultured cells. J Cell Biol 108:1453-1463.

Rao-Mirotznik R, Harkins AB, Buchsbaum G, Sterling P (1995) Mammalian rod terminal: architecture of a binary synapse. Neuron 14:561-569.

Rashid DJ, Wedaman KP, Scholey JM (1995) Heterodimerization of the two motor subunits of the heterotrimeric kinesin, $\mathrm{KRP}_{85 / 95}$. J Mol Bio 252:157-162.

Raviola E, Gilula NB (1975) Intramembrane organization of specialized contacts in the outer plexiform layer of the retina. A freeze-fracture study in monkeys and rabbits. J Cell Biol 65:192-222.

Redburn D (1988) Transmitter systems in the outer plexiform layer of the mammalian retina. Neurosci Res [Suppl] 8:S127-S136.

Sawin KE, Mitchison TJ, Wordeman LG (1992) Evidence for kinesinrelated proteins in the mitotic apparatus using peptide antibodies J Cell Sci 101:303-313.

Schaeffer SF, Raviola E (1978) Membrane recycling in the cone cell endings of the turtle retina. J Cell Biol 79:802-825.

Schaeffer SF, Raviola E, Heuser JE (1982) Membrane specializations in the outer plexiform layer of the turtle retina. J Comp Neurol 204:253-267.

Schmitz F, Bechmann M, Drenckhahn D (1996) Purification of synaptic 
ribbons, structural components of the photoreceptor active zone complex. J Neurosci 16:7109-7116.

Scholey JM (1996) Kinesin-II, a membrane traffic motor in axons, axonemes, and spindles. J Cell Biol 133:1-4.

Sjöstrand FS (1953) The ultrastructure of the retinal rod synapse of the guinea pig eye. J Appl Physiol 24:1422.

Sjöstrand FS (1998) Structure determines function of the retina, a neural center. 1. The synaptic ribbon complex. J Submicrosc Cytol Pathol 30:1-29.

Tabish M, Siddiqui ZK, Nishikawa K, Siddiqui SS (1995) Exclusive expression of $C$. elegans osm-3 kinesin gene in chemosensory neurons open to the external environment. J Mol Biol 247:377-389.

Troutt LL, Burnside B (1988) Microtubule polarity and distribution in teleost photoreceptors. J Neurosci 8:2371-2380.

Ulrich B, Südhof TC (1994) Distribution of synaptic markers in the retina: implications for synaptic vesicle traffic in ribbon synapses. J Physiol (Lond) 88:249-257.

Vale RD, Reese TS, Sheetz MP (1985) Identification of a novel forcegenerating protein, kinesin, involved in microtubule-based motility. Cell 42:39-50.

Vashishtha M, Walther Z, Hall JL (1996) The kinesin-homologous protein encoded by the Chlamydomonas FLA10 gene is associated with basal bodies and centrioles. J Cell Sci 109:541-549.
Vernos I, Raats J, Hirano T, Heasman J, Karsenti E, Wylie C (1995) Xklp1, a chromosomal Xenopus kinesin-like protein essential for spindle organization and chromosome positioning. Cell 81:117-127.

von Gersdorff H, Matthews G (1994) Dynamics of synaptic vesicle fusion and membrane retrieval in synaptic terminals. Nature 367:735-739.

von Gersdorff H, Matthews G (1997) Depletion and replenishment of vesicle pools at a ribbon-type synaptic terminal. J Neurosci 17:1919-1927.

Wedaman KP, Meyer DW, Rashid DJ, Cole DG, Scholey JM (1996) Sequence and submolecular localization of the $115-\mathrm{kD}$ accessory subunit of the heterotrimeric kinesin-II $\left(\mathrm{KRP}_{85 / 95}\right)$ complex. J Cell Biol 132:371-380.

Yamazaki H, Nakata T, Okada Y, Hirokawa N (1995) KIF3A/B: a heterodimeric kinesin superfamily protein that works as a microtubule plus end-directed motor for membrane organelle transport. J Cell Biol 130:1387-1399.

Yamazaki H, Nakata T, Okada Y, Hirokawa N (1996) Cloning and characterization of KAP3: a novel kinesin superfamily-associated protein of KIF3A/3B. Proc Natl Acad Sci USA 93:8443-8448.

Yang Z, Goldstein LSB (1998) Characterization of the KIF3C neural kinesin-like motor from mouse. Mol Biol Cell 9:249-261.

Yen TJ, Li G, Schaar BT, Szilak I, Cleveland DW (1992) CENP-E is a putative kinetochore motor that accumulates just before mitosis. Nature 359:536-539. 